\title{
PLANEJAMENTO E GESTÃO DO TURISMO DURANTE A COVID-19 NAS REGIÕES TURÍSTICAS DE BELÉM E CAMPOS DO MARAJÓ
}

\author{
TOURISM PLANNING AND MANAGEMENT DURING THE COVID-19 PANDEMIC IN THE TOURIST REGIONS OF BELÉM \\ AND CAMPOS DO MARAJÓ
}

\author{
PLANIFICACIÓN Y GESTIÓN DEL TURISMO DURANTE EL COVID-19 EN LAS REGIONES TURÍSTICAS DE BELÉM Y \\ CAMPOS DO MARAJÓ
}

\section{RESUMO}

O quadro pandêmico instalado nas inúmeras regiões do planeta teve impactos significativos na atividade turística mundial. Neste artigo serão analisadas 02 regiões turísticas: a Região Turística de Belém e a Região Turística dos Campos do Marajó. 0 objetivo será a análise do planejamento e a gestão do turismo mediante a implementação de medidas sanitárias, de distanciamento social e demais políticas mitigadoras dos impactos da pandemia da covid-19 e sua aplicabilidade nas realidades dos municípios Belém, Soure e Salvaterra, representativos para as duas regiões turísticas. A pesquisa foi de natureza qualitativa, com revisão bibliográfica e documental dos instrumentos de gestão criados em 2020, tanto em nível federal quanto em nível estadual e municipal. Realizou-se a análise documental de leis, planos e decretos federais e das prefeituras de Belém, Soure e Salvaterra, afim de mitigar os impactos socioeconômicos da covid-19 nas atividades turísticas. Por fim, realizaram-se entrevistas semiestruturadas gravadas via plataforma Google Meet com representantes do poder público, ligados ao planejamento e gestão das regiões turísticas de Belém e Campos do Marajó; e com representantes de entidades da Sociedade Civil Organizada, principalmente aqueles ligados ao mercado. A partir da análise das medidas sanitárias de restrição à circulação de pessoas e ao transporte; das entrevistas realizadas com representantes de organizações do trade turístico e representantes dos órgãos públicos estaduais e municipais e da análise das principais estratégias pensadas para o período pós-pandemia da covid-19, aponta-se que a pandemia impactou de forma significativa no setor do turismo durante o ano de 2020.

Palavras-chave: Turismo. Pandemia. Pará. Belém. Marajó.

\section{ABSTRACT}

The pandemic situation in countless regions of the planet had significant impacts on the world tourism activity. The present article addresses this issue based on the cases of two tourist regions: the Tourist Region of Belém and the Tourist Region of Campos do Marajó. It aims to analyze the tourism planning and management carried out through the implementation of sanitary measures, social distancing and other policies aimed at mitigating the impacts of the Covid-19 pandemic, and their applicability in the realities of the municipalities of Belém, Soure and Salvaterra. A qualitative research study was conducted, using data collected through a bibliographical review and a documentary research on the management instruments created in 2020, both at the federal and at the state and municipal levels of government. A documentary analysis of the laws, plans and decrees made by the federal government and the municipalities of Belém, Soure and Salvaterra with the aim of mitigating the socioeconomic impacts of covid-19 in tourist activies. Finally, recorded semistructured interviews were done, via the Google Meet platform, both with government representatives involved in the planning and management of the tourist regions of Belém and Campos do Marajó; and with representatives of Civil Society Organizations, mainly those linked to the market. Based on the analysis of the sanitary measures aimed at restricting the movement of people and transportation; on the interviews with representatives of tourist trade organizations and state and municipal government agencies; and on the analysis of the main strategies designed for the post-pandemic period, the article concludes that the pandemic had a significant impact on the tourism sector during the year 2020.

\section{Ágila Flaviana Alves Chaves Rodrigues a}

(D) Kássia Suelen da Silva Farias ${ }^{a}$

(D) Maria Goretti da Costa Tavares ${ }^{\text {a }}$

Dilene de Cássia Santos de Castro $^{a}$

a Universidade Federal do Pará (UFPA), Belém, PA, Brasil

DOI: $10.12957 /$ geouerj.2021.61314

Correpondência: agflaviana@gmail.com

Recebido em: 1 mar. 2021 Aceito em: 22 jun.2021 


\section{RESUMEN}

La instauración del cuadro pandémico en numerosas regiones del planeta impactó considerablemente a la actividad turística mundial. En este artículo se analizarán 02 regiones turísticas: la Región Turística de Belém y la Región Turística de Campos do Marajó. El objetivo será analizar la planificación y gestión del turismo a través de la implementación de medidas sanitarias de distanciamiento social y otras políticas para mitigar los impactos de la pandemia del COVID-19 y su aplicabilidad en los municipios Belém, Soure y Salvaterra, representante de las dos regiones turísticas. La investigación fue de carácter cualitativo, y contó con una revisión bibliográfica y documental de los instrumentos de gestión creados en 2020 a nivel federal, estatal y municipal. Se realizó un análisis documental de las leyes, planes y decretos federales y de los municipios de Belém, Soure y Salvaterra para mitigar los impactos socioeconómicos del covid-19 en las actividades turísticas. Finalmente, se llevaron a cabo entrevistas semiestructuradas grabadas en la plataforma Google Meet con representantes del poder público, vinculados a la planificación y gestión de las regiones turísticas de Belém y Campos do Marajó; y con representantes de los organismos de la Sociedad Civil Organizada, en especial aquellos vinculados al mercado. Partiendo del análisis de las medidas sanitarias de restricción a la circulación de personas y al transporte; de las entrevistas con representantes de organizaciones del comercio turístico y representantes de entes públicos estaduales y municipales, así como también del análisis de las principales estrategias ideadas para el período pos-pandemia del COVID-19, se señala que la pandemia impactó significativamente al sector turístico durante el año 2020.

Palabras-clave: Turismo. Pandemia. Pará. Belém. Marajó. 


\section{INTRODUÇÃO}

Desde o final do ano de 2019, a crise pandêmica ocasionada pela covid-19 tem gerado uma recessão global de ampla magnitude, entre os quais dois aspectos têm sido essenciais para entendê-la: a saúde e a economia. O quadro pandêmico instalado nas inúmeras regiões do planeta passou a refletir sobre as fragilidades existentes nas diferentes instâncias da vida social (política, econômica, cultural e espacial) do sistema capitalista, cujos impactos nos países, ditos periféricos, ganharam proporções ainda mais catastróficas.

Desde antes de 2018, consolidam-se inúmeras mudanças que culminam em profundas reflexões sobre o futuro da democracia no Brasil, como o retorno efetivo da abertura econômica do país para o capital internacional e o reforço ao empresariamento urbano, que busca condicionar simbolicamente as cidades como inteligentes, criativas e sustentáveis, por vezes, deixando de lado políticas sociais e de saúde pública que poderiam, nesse momento, amenizar os impactos da covid-19.

Na Amazônia, em especial no Estado do Pará, anteriormente ao período pandêmico, uma série de políticas e projetos públicos como o Plano Ver-o-Pará e o relatório do Plano de Desenvolvimento Integrado do Turismo Sustentável (PDITS) dos Polos Belém, Tapajós e Marajó para o Programa de Desenvolvimento do Turismo, o PRODETUR (PARÁ, 2011) demonstravam que o crescimento econômico e a competitividade empresarial tornam-se ingredientes fundamentais da fórmula mercadófila do planejamento urbano. Assim, desde 2016, vinha-se estabelecendo uma série de instrumentos para elencar o turismo e a gastronomia entre as cadeias produtivas do Plano Estratégico de Desenvolvimento Sustentável do Estado (Pará 2030).

Mais recentemente, instituiu-se o novo reordenamento turístico do Estado do Pará, criado por meio da Portaria no 164/2019/GEPS/SETUR, que dispõe sobre a divisão em 14 Regiões Turísticas (PARÁ, 2020) ${ }^{1}$. Nessa constituição, interessa para este estudo a Região Turística de Belém, composta pelos municípios de Belém, Ananindeua, Benevides, Marituba e Santa Bárbara do Pará, em especial, a capital do Estado; e a Região Turística dos Campos do Marajó formada pelos municípios de Cachoeira do Arari, Ponta de Pedras, Santa Cruz do Arari, Salvaterra e Soure, sendo representativos os dois últimos.

Dentre as atividades características do turismo em Belém, destacam-se as dos segmentos denominados "turismo de negócios e eventos", seguidas daquelas que se utilizam da valorização de paisagens culturais e ecológicas, como os segmentos do "turismo de natureza ou ecoturismo" e do "turismo cultural". Nos últimos

\footnotetext{
${ }^{1}$ As novas regiões turísticas do estado do Pará são: I - Região Turística de Belém; II - Região Turística Amazônia Atlântica Guamá; III Região Turística do Capim; IV - Região Turística Amazônia Atlântica Caeté; V - Região Turística do Araguaia; VI - Região Turística do Carajás; VII - Região Turística do Tocantins; VIII - Região Turística do Lago de Tucuruí; IX - Região Turística do Baixo Tapajós; X - Região Turística do Alto Tapajós; XI- Região Turística do Rio Amazonas; XII - Região Turística dos Campos do Marajó; XIII - Região Turística das Florestas do Marajó; XIV - Região Turística do Xingu (PARÁ, 2019). O novo reordenamento substitui o anterior que dividia o estado em 06 Polos Turísticos, sendo estes: Belém, Amazônia Atlântica, Marajó, Tapajós, Xingu e Araguaia-Tocantins (PARÁ, 2001).
} 
anos, os apelos governamentais voltam-se para as paisagens de beira de rio, encontradas na orla e nas ilhas, como também nas intervenções no ambiente ecológico (RODRIGUES, 2018).

Na Região Turística dos Campos do Marajó, os municípios em destaque podem ser acessados via fluvial ou aérea, devido a existência de portos e pequenas pistas de pouso, em sua maioria, precárias e particulares. Nas práticas turísticas, os municípios de Soure e Salvaterra ganham relevância por serem considerados “os portões de entrada" do arquipélago, localizados acerca de 87 quilômetros de distância de Belém a partir do porto de Camará, em Salvaterra (MEGUINS, 2018). A parte urbana desses municípios é representada pelas pequenas atividades comerciais e, a parte rural constituída por fazendas e comunidades costeiras que, por vezes, tem a renda complementada pelo turismo rural. Nas comunidades praianas, ganha evidência o turismo de "sol e praia" e de base comunitária (TBC), possibilitado, principalmente, pelo apoio de programas governamentais surgidos a partir da década de 1970 (PARÁ, 2009).

Por ser uma categoria específica nas políticas de planejamento e gestão urbana, a produção espacial em áreas potencialmente turísticas acontece sob "a atuação do Estado, do capital e da sociedade". Esses agentes utilizam os locais de maneira diferenciada, visando a interesses particulares às suas esferas de poder (MOLINA, 2007, p. 16). Assim, há o interesse em analisar como vem sendo pensado o planejamento e a gestão do turismo mediante a implementação de medidas sanitárias, de distanciamento social e demais políticas mitigadoras dos impactos da pandemia da covid-19, e sua aplicabilidade nas realidades dos municípios Belém, Soure e Salvaterra, o primeiro representativo para região turística de Belém e os dois últimos para a região turística de Campos do Marajó.

Entende-se que a pesquisa é de natureza qualitativa, com revisão bibliográfica, análise documental e de conteúdo dos instrumentos de gestão criados em 2020, tanto em nível federal quanto estadual e municipal. Por meio do acesso aos documentos, pôde-se não somente interpretá-los, mas de maneira dedutiva, reconstruir as informações e, a partir das suas inferências, analisar suas composições. Esse momento foi fundamental para a apreensão crítica das decisões políticas e entendimento sobre a importância do estabelecimento de redes de cooperação ocasionadas na crise pandêmica.

Lançou-se mão ainda de entrevistas semiestruturadas gravadas via plataforma Google Meet com representantes do poder público dos municípios de Belém, Soure e Salvaterra, ligados ao planejamento e gestão das duas Regiões Turísticas; e com representantes de entidades da Sociedade Civil Organizada, principalmente, aqueles ligados ao mercado, selecionados por sua representatividade e por seu destaque em diferentes escalas de atuação².

\footnotetext{
2 Em nível estadual foram entrevistados os seguintes representantes: Secretaria de Estado de Turismo (SETUR-PA); Associação Brasileira de Bares e Restaurantes (ABRASEL-PA); Associação Brasileira de Assessores e Cerimonialistas (ABRACS-PA); Associação Brasileira de Agências de Viagens (ABAV-PA); Associação Brasileira da Indústria de Hotéis (ABIH-PA); Conselho Empresarial de
} 
Diante disso, o presente estudo discute sobre as ações do Estado na produção do espaço em tempos de covid-19, considerando os municípios de Belém, Soure e Salvaterra, expressivos para as dinâmicas do turismo nas Regiões Turísticas elencadas. Busca-se, assim, mostrar, em um primeiro momento, as estratégias políticas por parte do poder público federal, responsável por configurar lógicas cuja base é estabelecida por uma ordem distante (LEFÈBVRE, 2001), ligada às dinâmicas das instituições internacionais, que, por vezes, ofusca ou não atinge demandas mais urgentes ligadas ao cotidiano e às especificidades locais, como apresentado nos dados do emprego e nas linhas de apoio financeiro.

No segundo momento, apresentam-se as estratégias políticas de ordem próxima (LEFÈBVRE, 2001), reveladas pelo planejamento e gestão do turismo nas esferas estadual e municipal, bem como a percepção dos representantes das entidades de classe ligadas ao mercado turístico local quanto a aplicabilidade das medidas sanitárias e de mitigação dos impactos socioeconômicos da covid-19. Parte-se do pressuposto de que as medidas iniciais implementadas entre as instâncias do poder público, gera processos burocráticos que oportunizam o não cumprimento das resoluções e demandas que se propõem a resolver.

\section{Estratégias políticas distantes em tempos de pandemia}

É certo que a pandemia ou surtos endêmicos não são algo novo no mundo. A transferência de doenças do velho mundo para os habitantes da América, Austrália, Pacífico, é um pequeno exemplo exposto por Hall, Scott, Gossling (2020) e Silva et al. (2020) que demonstram o quão o planeta passou por transformações e (re)adaptações. Sinaliza-se que as (re)adaptações causadas pelos surtos endêmicos não causaram um impacto isolado, há transformações no ecossistema, nas relações sociais, na economia, na educação e na política. E, como ressaltam Hall, Scott e Gossling (2020, p. 578), foram essenciais "para a transformação, por causa do seu enorme impacto à demografia e os efeitos que isso teve nos sistemas de produção e na capacidade das sociedades se adaptarem às mudanças externas.

Ainda que a sociedade atual seja referência em processos tecnológicos, de globalização e de inovação, com um crescimento acentuado de antibióticos no mercado farmacêutico; há, no entanto, a indicação de que as mudanças socioambientais ocasionadas por esse ritmo acelerado possam contribuir de forma significava para o surgimento de novas doenças na sociedade pós-moderna (HALL, SCOTT, GOSSLING, 2020; SILVA et al, 2020). Para os autores, a grande aceleração da devastação ambiental, elevada taxa demográfica dos centros

Turismo e Hospitalidade da Federação do Comércio de Bens, Serviços e Turismo no Estado do Pará (CETUR/FECOMERCIO-PA); Sindicato dos Guias de Turismo do Pará (SINGTUR-PA). Em nível municipal foram entrevistados os seguintes representantes: Serviço Brasileiro de Apoio às Micro e Pequenas Empresas (SEBRAE Belém e SEBRAE Soure); Coordenadoria Municipal de Turismo do município de Belém (BELEMTUR); Secretaria de Turismo, Esporte e Cultura de Soure (SECTUR); Associação de Turismo do Marajó (ATM). 
urbanos, urbanização e facilitação de conexão entre diferentes países e regiões são fatores que podem acelerar o surto de novas doenças.

Nesse bojo, a pandemia da covid-19 não pode ser interpretada enquanto uma crise econômica, ainda que pareça ser óbvio, mas trata-se de "una crisis de salud publica que tiene efectos inevitables en el resto de las dimensiones sociales" (GONZÁLEZ, 2020 p. 141). E, nesse contexto, está o turismo, compreendido enquanto um fenômeno econômico e social, que está envolvido nas principais decisões dos governos, seja para a aplicação de medidas mais restritivas, que inviabilizam as viagens ou pelos efeitos econômicos gerados às empresas do setor de transporte, de hospedagem, alimentação e entre outros.

A questão política a ser pensada em meio a covid-19 foi basicamente a tentativa de equilibrar ao mesmo tempo: 1) a crise de saúde, a partir da criação de medidas sanitárias, que vão desde as medidas mais básicas, como a higienização das mãos e utilização de máscara até medidas mais restritivas, como o bloqueio das fronteiras e isolamento social e; 2) a instabilidade da economia, causada pelos impactos no setor, que forçou os países a criar medidas de recuperação econômica (GONZÁLEZ, 2020). No entanto, como observa o autor, essa crise global serviu como oportunidade para mudar a forma de articulação e as estratégias dos governos, bem como o foco em modelos políticos que sejam menos baseados em crescimento econômico e mais orientados para as dinâmicas da sustentabilidade ambiental, social e para inovação tecnológica.

Diante dos impactos ocasionados no turismo mundial, a Organização Mundial do Turismo (OMT) apresentou em abril de 2020 um conjunto de diretrizes preparadas por um Comitê de Crise Mundial do Turismo cujo objetivo principal era apoiar e direcionar os setores público e privado para a recuperação diante da crise da pandemia. Nesse documento, 23 medidas são elencadas, as quais foram divididas em três âmbitos principais, a saber: 1) gestão de crise e diminuição dos efeitos; 2) estímulo e aceleração da recuperação e; 3 ) preparação para o Futuro (OMT, 2020).

As duas primeiras estabelecem um conjunto de medidas de cunho mais econômico e social, a exemplo de apoio à liquidez das empresas; estímulos financeiros; revisão de impostos e taxas; proteção a população mais vulnerável, de modo que seja possível garantir a manutenção de postos de trabalho, principalmente. Já o terceiro aspecto traça medidas que perpassam por um comprometimento sustentável e inovação tecnológica, no qual insere, dentre outros aspectos, os Objetivos de Desenvolvimento Sustentável (ODS) expostos na Agenda 2030; o fortalecimento da governança no turismo e investimento em sistemas de inteligência.

Assim, as novas tecnologias da globalização permitiram ampliar a chegada das redes de informações que transmitem e impõem ordens distantes à ordem próxima (LEFÈBVRE, 2001), uma vez que as articulações dos instrumentos estabelecidos pela Organização Mundial do Turismo (OMT) são baseadas nas orientações 
da Organização Mundial de Saúde (OMS), mas adaptadas às imposições de um mercado que atinge de forma indistinta todos os locais.

Como observado por González (2020), ainda que se anuncie estratégias para a sustentabilidade no turismo em meio à crise ocasionada pela pandemia, a maior parte das medidas anunciadas pela OMT se vinculam a um modelo tradicional de turismo, que permite proteger, a partir de instrumentos financeiros, principalmente, o mercado.

Esse fato se justifica, sobretudo, pela importância econômica que o turismo gera para os destinos turísticos, a taxa de dependência de regiões e países para o turismo é significativa, à exemplo de Portugal onde "o turismo participa com 13,7\% da composição do PIB nacional, na Espanha tem-se algo em torno de 12,3\%; na França, 9,5\%; na Grã-Bretanha 9\%; na Itália 5\%; no Brasil, 3,7\% e nos Estados Unidos 2,6\%" (CRUZ, 2020, p. 6). A porcentagem do turismo no PIB do Brasil e Estados Unidos é relativamente baixa comparado aos demais, contudo, com a crise pandêmica gerou-se um impacto acentuado.

Em nível nacional, o turismo teve um impacto negativo de 301.469 postos de trabalhos e reitera-se que, mesmo que o saldo dos meses de setembro a dezembro tenha sido positivo, não foi o suficiente para recuperar a perda do setor. Entre os segmentos de turismo mais impactados estão: alimentação, com -182.984; alojamento (hotéis e outros tipos de alojamento) com uma perda de -59.791; agências de viagem, com -20.761 e transporte aéreo, com -8.305 postos de trabalho (TEBERGA, 2020) ${ }^{3}$.

Ao comparar o PIB do setor em 2019, as perdas geradas no Brasil para o biênio 2020-2021, somam-se $\mathrm{R} \$ 116,7$ bilhões, isto representa uma perda de $21,5 \%$ do período, conforme os estudos da Fundação Getúlio Vargas (FGV, 2020). Entre as medidas sinalizadas pela FGV para a recuperação do setor estão: 1) disponibilização de créditos; 2 ) reequilíbrio dos contratos que interferem no setor como os de aeroportos e centro de eventos; 3) criação de linhas de créditos específicas aos microempreendedores; 4) promoção de incentivo ao turismo doméstico e, por último; 5) crédito para as operadoras e consumidores para viabilizar o retorno no setor.

No Brasil, o Ministério de Turismo (MTUR) criou instrumentos políticos para o setor nesse período de crise, como pode-se resumir no Quadro 1:

Quadro 1. Brasil: medidas políticas adotadas pelo MTUR no período de crise pandêmica. Fonte: As autoras com base em Brasil (2020a; 2020b e 2020c), Lei № 14.046, de 24 de agosto de 2020 e Lei №14.051, de 08 de setembro de 2020.

\footnotetext{
${ }^{3}$ Algumas das informações referentes aos impactos econômicos e sociais gerados pela Covid 19 nos municípios selecionados encontram-se no artigo intitulado "O turismo no Pará e a covid-19: diversidade econômica e políticas públicas regionais a partir do impacto da pandemia" deste dossiê, que também conta com a participação das autoras.
} 


\begin{tabular}{|c|c|c|}
\hline Instrumento político & Objetivo & Valor \\
\hline $\begin{array}{l}\text { Lei } n \text { o } 14.046 \text {, de } 24 \text { de agosto } \\
2020 \text { (Oriundo da Medida } \\
\text { Provisória no } 948 \text {, de } 8 \text { de abril } \\
\text { de } 2020 \text { ) }\end{array}$ & $\begin{array}{l}\text { Dispõe sobre o adiamento e o cancelamento de serviços, } \\
\text { de reservas e de eventos dos setores de turismo e de } \\
\text { cultura em razão do estado de calamidade pública }\end{array}$ & \\
\hline $\begin{array}{l}\text { Selo do Turismo Responsável e } \\
\text { Seguro ( } 5 \text { de junho de 2020) }\end{array}$ & $\begin{array}{l}\text { Protocolos de biossegurança específicos para a volta em } \\
\text { segurança da atividade turística }\end{array}$ & \\
\hline $\begin{array}{l}\text { Lei no } 14.051 \text {, de } 8 \text { de setembro } \\
\text { de } 2020 \text { (oriundo da Medida } \\
\text { Provisória no } 963 / 20 \text { ) }\end{array}$ & $\begin{array}{l}\text { Crédito Extraordinário - Financiamento da Infraestrutura } \\
\text { Turística Nacional (Recursos sob Supervisão do Fundo } \\
\text { Geral de Turismo/FUNGETUR - Ministério do Turismo). }\end{array}$ & $R \$ 5.000 .000 .000,00$ \\
\hline $\begin{array}{l}\text { Plano de Retomada do Turismo } \\
\text { brasileiro (10 de novembro de } \\
\text { 2020) }\end{array}$ & $\begin{array}{l}\text { Plano direcionado para entidades relacionadas à cadeia } \\
\text { do turismo para uma ação conjunta, a fim de mitigar o } \\
\text { impacto socioeconômico da covid-19 e acelerar a } \\
\text { recuperação do setor. }\end{array}$ & \\
\hline
\end{tabular}

A primeira medida realizada pelo Órgão Oficial de Turismo no Brasil foi para atender o consumidor e as empresas, tendo em vista o vultoso número de cancelamento de serviços em decorrência das restrições sociais, a exemplo da remarcação e cancelamento de voos nacionais e internacionais. Esse fato, específico da remarcação de voos, teve início com um acordo realizado entre o MTUR e a Defesa do Consumidor do Ministério da Justiça e Segurança Pública, realizado em março de 2020, visto a pressão política para orientar turistas e empresários.

A criação tardia de medidas políticas, específicas para o turismo no Brasil em meio a pandemia, é justificada pelo negacionismo provocado pelo Governo federal, que menosprezou o acentuado grau de transmissão e letalidade causado pela covid-19, posicionando-se, portanto, contrário às recomendações anunciadas pela Organização Mundial da Saúde (OMS) e dos cientistas da área da saúde.

Mensagens contraditórias ou inaplicáveis por parte da Presidência da República resultam na ampliação dos riscos e impactos. Por um lado, resultam em um enfrentamento parcial e incompleto da pandemia, interferindo negativamente e atrasando o impacto das medidas de distanciamento social que podem salvar vidas. Por outro, refletem uma disputa política em que uma grave crise sanitária pode ser sobreposta por uma crise política, prolongando e ampliando os impactos negativos da pandemia por COVID-19 (FUNDAÇÃO OSWALDO CRUZ, 2020, p. 7).

Uma das medidas encontradas para suprir as necessidades das empresas, de forma geral, foi o Programa Emergencial de Suporte a Empregos (PESE), que permitiu o financiamento de até quatro folhas de pagamento salarial de empregados ou de verbas trabalhistas, a partir da criação da Medida provisória (MP) no 944 em abril de 2020. Em agosto de 2020, a Lei no 14.043 foi então sancionada, alterando alguns requisitos para acesso ao financiamento, entre os quais está a possibilidade de empresas que têm receita bruta igual ou inferior a $R$ $\$ 50.000 .000,00$ (cinquenta milhões de reais). 
A MP no 975 de junho de 2020, convertida na Lei no 14.042 em agosto de 2020, instituiu o Programa Emergencial de Acesso a Crédito (PEAC). Este, por sua vez, objetivou facilitar o acesso a créditos em virtude do impacto da covid-19, destinado a empresas de pequeno e médio porte, a associações ou fundações de direito privado e a sociedades cooperativas.

Outro recurso direcionado aos empresários de turismo foi o Programa Nacional de Apoio às Microempresas e Empresas de Pequeno Porte (PRONAMPE), instituído em maio de 2020 pela Lei no 13.999, que dispõe uma linha de crédito para a realização de investimentos ou para a quitação de despesas operacionais, com um prazo de 36 meses para pagamento.

Tendo em vista o último instrumento criado pelo MTUR, em novembro de 2020, o Plano de Retomada do Turismo teve estratégias voltadas para quatro eixos estratégicos, destacados: 1) preservação de empresas e empregos no setor de turismo; 2) melhoria da estrutura e qualificação de destinos; 3) implantação dos protocolos de biossegurança e; 4) promoção e incentivo às viagens (BRASIL, 2020c).

O auxílio financeiro apresentado no Plano de Retomada do Turismo dispõe de um crédito de $\mathrm{R} \$$ bilhões, já previsto na Lei no 14.051/2020, que destina os valores ao Fundo Geral do Turismo (FUNGETUR) e distribui para as instituições financeiras das regiões do Brasil. Vale ressaltar que o FUNGETUR consiste em uma linha de crédito criada em 1971, que visa fomentar e prover recursos para empresas de pequeno e médio porte, pequenas e médias empresas turísticas e governos locais (BRASIL, 1975).

Conforme o relatório estatístico do FUNGETUR, apresentado em dezembro de 2020 (BRASIL, 2020a) houve um aumento significativo do financiamento contratado no referido ano, isto é, comparado ao total de 2018, foi um crescimento de $948 \%$ e de $506 \%$ em relação a 2019 , o que demonstra o grande impacto econômico gerado pela Pandemia em 2020. Além disso, outro fato importante a ser evidenciado é que cerca de $70 \%$ do montante contratado no FUNGETUR foi destinado ao micro e pequeno empresários e ao microempreendedor individual (MEI), totalizando R\$ 512 milhões em 2020.

É válido destacar que as perdas econômicas seguem uma evolução face ao avanço (re)anunciado no primeiro semestre de 2021, sobretudo na região Norte do Brasil, especificamente em Manaus, capital do Estado do Amazonas, onde foi constatado uma variante do SARS-cov-2 com um elevado avanço de propagação na região.

Os valores empenhados em 2020 para instituições bancárias da região Norte, como o Banco da Amazônia (BASA) e Banco do Pará (BANPARÁ) foram de $\mathrm{R} \$ 500.000 .000,00$ (quinhentos milhões) e $\mathrm{R} \$ \$$ $50.000 .000,00$ (cinquenta milhões), respectivamente (Figura 1). É válido destacar, que conforme o documento publicado pelo Mtur (BRASIL, 2020b), desde 2017 não havia sido destinado nenhum recurso advindo do FUNGETUR para a região Norte do Brasil e que os valores empenhados até dezembro de 2020, não haviam 
sido utilizados. Desse modo, não foi possível identificar nenhum valor do FUNGETUR para as Regiões Turísticas de Belém e Campos do Marajó.

Figura 1. Valor total da Lei 14.051/2020 empenhado por instituição. Fonte: Brasil, 2020b

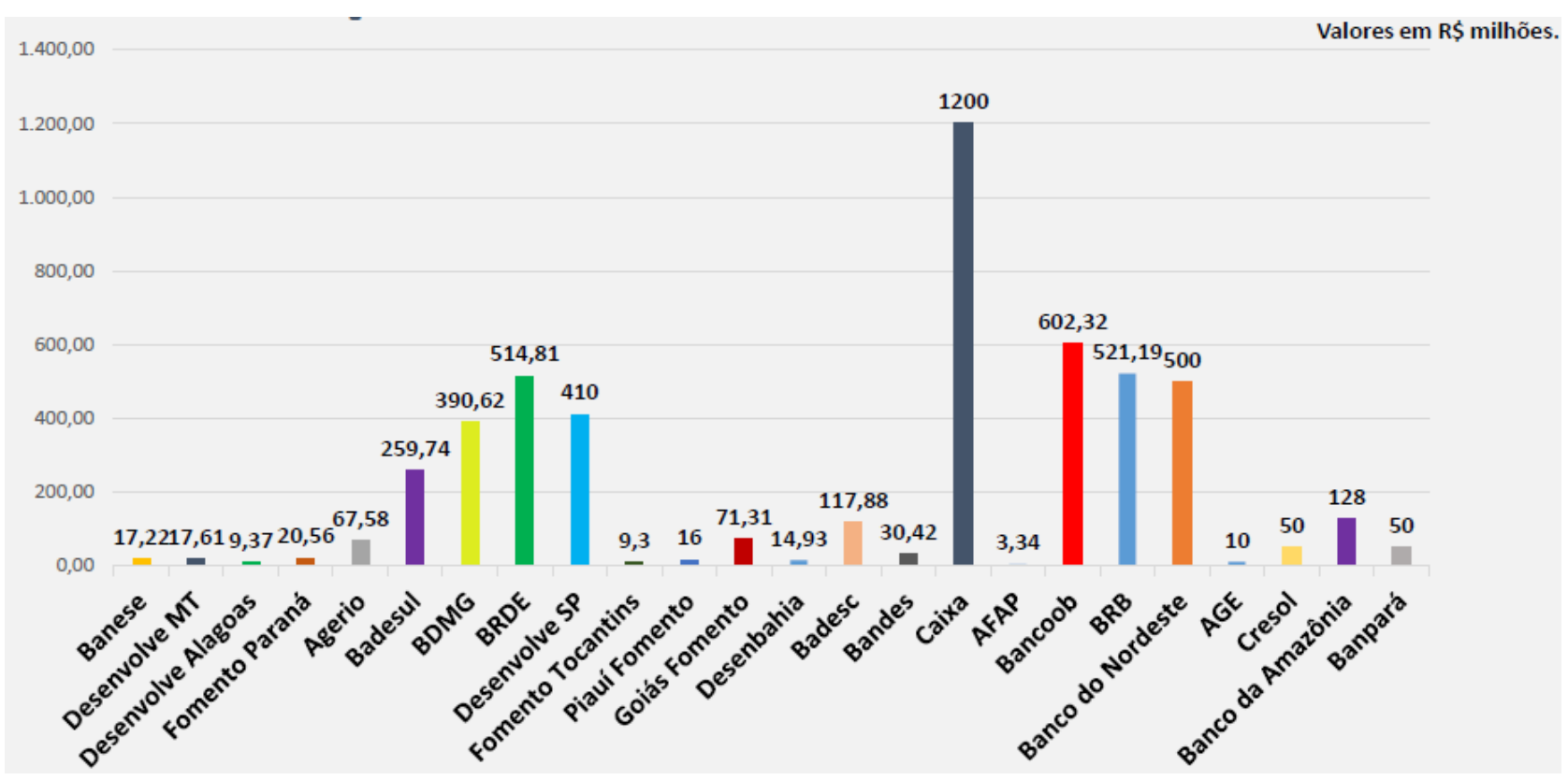

O planejamento do turismo diante da pandemia da covid-19, reforça o quanto as relações próximas se tornam cada vez mais dependentes das relações globais. As instituições que correspondem às superestruturas que regulam o turismo, como a Organização Mundial do Turismo (OMT) e, em nível nacional, o Ministério do Turismo (MTUR), são responsáveis por promover e legitimar os mecanismos de ação e de produção das normas turísticas, seguidas pelos governos estaduais e municipais, o que requer integrações e negociações diversas, contudo, as estratégicas precisam ser bem fiscalizadas e articuladas aos interesses coletivos locais, onde as demandas prioritárias básicas, nesse caso, programas e medidas sociais, saúde, sanitárias e econômicas, como será visto a seguir, não devem ser ignoradas ou desassistida pelo poder público, principal articulador das diferentes interfaces entre o público e o privado.

Políticas e medidas de enfrentamento dos impactos da covid-19 pela gestão pública e a percepção dos representantes das organizações ligadas às regiões turísticas de Belém e Campos do Marajó

Belém, capital do estado do Pará, pertencente à Região Turística de Belém, nos últimos anos ganhou destaque nos veículos de comunicação locais e nacionais, por sua centralidade, que além de oferecer a melhor infraestrutura urbana e serviços logísticos da região, vem despontando por seu potencial cultural gastronômico. As ações apresentadas nos planos e nos projetos culturais e de turismo, afirmam que a culinária 
paraense desponta como a que melhor representa o Brasil, por suas características peculiares que remetem à origem indígena, o que the conferiu o título de Cidade Criativa da Gastronomia, conferido pela UNESCO, no ano de 2015, incentivando a promoção do turismo e a geração de novos empregos (PARÁ, 2017).

As cidades de Soure e Salvaterra, localizadas na Região Turística de Campos do Marajó, tornam-se representativas por possuírem a melhor infraestrutura em transportes, serviços públicos e condições de acesso, bem como pela proximidade com a capital do estado. Nos dois municípios ganham destaque o turismo do tipo rural nas fazendas que, além das atividades primárias, como a criação e comercialização de produtos provenientes dos rebanhos bovinos e bubalinos, pequenas e médias plantações de frutas regionais, vem comercializando roteiros e venda de produtos pelas propriedades. Destaca-se ainda as comunidades praianas da região, onde ganha evidencia o turismo de "sol e praia" e de base comunitária (TBC) (PARÁ, 2009). Houve ainda o fomento para a instalação de pousadas, financiadas com recursos da Superintendência de Desenvolvimento da Amazônia (SUDAM), por considerar "vocação natural" desta região para a atividade turística (FIGUEIREDO, 1998).

Ressalta-se que os três municípios selecionados como expressivos para a análise das duas regiões turísticas fazem parte do novo Mapa do Turismo Brasileiro, no qual Belém está classificada na categoria A, Soure na categoria C e Salvaterra na categoria D (BRASIL, 2019).

Assim, com o advento da pandemia houve uma intensa mobilização das instituições políticas e sociais, seja para conter o avanço das infecções nos países, estados e municípios ou para encontrar medidas sociais e econômicas de recuperação das diferentes realidades. Dentre as políticas e medidas sanitárias de enfrentamento da covid-19, praticadas em nível municipal e estadual, destacam-se as primeiras as ações desenvolvidas no primeiro semestre de 2020: em nível estadual: Lei no 9.051 de 14 de maio de 2020; município de Belém: Decreto № 95955 de 18 de março de 2020, Decreto № 96340 de 25 de maio de 2020 e Decreto no 96378 de 01 de junho de 2020; Soure: Decreto № 007 de Março de 2020 e Decreto № 009 de Março de 2020; e Salvaterra: Decreto no 07/2020 de 25 de março de 2020 e Procedimento Administrativo no 000194-343 de 4 de junho de 2020.

A implementação dessas medidas ocorre a partir da Lei no 13.979, de 6 de fevereiro de 2020, de âmbito nacional. Nesse sentido, o Pará sanciona a Lei no 9.051, de 14 de maio de 2020, onde objetivou a obrigatoriedade do uso de máscaras em todo o território paraense como medida de contenção à proliferação do vírus. Por conseguinte, Belém apresenta o Decreto no 95.955, de 18 de março de 2020, onde declara situação de emergência em saúde pública e cria Comitê de Operações de Emergência e Saúde Pública (COES) ${ }^{4}$

${ }^{4}$ Coordenado pela Secretaria Municipal de Saúde (SESMA). 
responsável por cuidar das ações técnicas e medidas operacionais de contingência da covid-19 no referido município.

As ações de enfrentamento elaboradas por Salvaterra por meio do Decreto no 07, de 25 de março de 2020, restringiram o acesso ao município de pessoas ou veículos com exceção de residentes e prestadores de serviços ou atividades essenciais. Assim como, proibiu a circulação ou permanência nas praias, realização de eventos e adotou medidas para evitar aglomeração nos estabelecimentos de serviços ou atividades essenciais. Posteriormente, no mês de junho, uma ação pública é realizada devido ao não cumprimento das ações estabelecidas por meio do decreto, direcionada para a fiscalização das atividades permitidas e pela crescente aglomeração de pessoas no comércio. A ação também menciona a autorização de abertura de hotéis, pousadas e templos religiosos no município frente ao aumento de casos de covid-19.

Em Soure, o decreto no. 007/2020 de 19 de março de 2020, disponibilizou medidas temporárias e emergenciais acerca da prevenção e contágio pela covid-19, assim como recomendações aos setores públicos e privados do município. Por conseguinte, o decreto no. 009/2020 de 21 de março de 2020 versou sobre medidas direcionadas a saúde pública no município por meio de um plano de contingência a ser seguido pelos cidadãos.

No âmbito estadual, destaca-se ainda, o Projeto “Abre Caminho”, elaborado pela SETUR, corroborado pelo Decreto estadual no 800, de 31 de maio de 2020, que institui o Programa RETOMAPARÁ, que dispõe sobre a retomada por meio da aplicação de medidas de distanciamento controlado e protocolos específicos para reabertura gradual e funcionamento de segmentos de atividades econômicas e sociais. Objetiva-se acelerar a retomada das atividades turísticas e a recuperação dos prejuízos causados pelas paralisações da pandemia da covid19, por meio de medidas mitigadoras e fomentadoras de novos negócios e fluxos turísticos (PARÁ, 2020) 5 .

De acordo com as diretrizes do plano de retomada, a SETUR vem realizando reuniões com representantes das entidades do trade turístico, técnicos da gestão municipal e academia por meio, principalmente, do Fórum Estadual de Turismo (FOMENTUR) na apresentação de protocolos de segurança e higiene aos estabelecimentos turísticos. Mesmo sem vacinação, no ano de 2020, as atividades foram gradativamente sendo liberadas pelos decretos, tendo ainda a Secretaria atuado na participação no lançamento do Plano Municipal de Turismo de Belém.

Em julho de 2020, foi lançada uma cartilha de orientações sobre parcerias com entidades bancárias e financeiras como o BANPARÁ, Banco da Amazônia, BNDES, Caixa Econômica e Banco do Brasil, além de bancos

\footnotetext{
${ }^{5}$ Na edição extra do Diário Oficial do Estado, publicada em 24 de julho de 2020, os espaços de visitação pública (museus e outros pontos turísticos) e a atividade do turismo foram definidos como abertos (autorizados), nos municípios com bandeira laranja e o transporte coletivo interestadual e intermunicipal de passageiros, terrestre, marítimo e fluvial, aberto para todas as bandeiras (PARÁ, 2020).
} 
privados e FUNGETUR. No caso das ações do Fundo Esperança, uma parceria da Secretaria de Estado de Desenvolvimento Econômico, Mineração e Energia do Pará (SEDEME) junto ao BANPARÁ e SEBRAE, as inscrições para participação do programa se encontram esgotadas, posto que o Programa atingiu o limite de crédito disponível, chegando a 100 mil inscrições ainda nos primeiros dias (PARÁ, 2020).

O projeto "Abre Caminho" conta com 22 diretrizes, cujas estratégias e ações mais discutidas entre os representantes do poder público e da iniciativa privada (Quadro 2) estão voltadas, sobretudo, para os seguintes eixos: 1) Fundo Esperança; 2) capital de giro; 3) novos canais de comunicação; 4) qualificação; 5) implementação de protocolos de segurança sanitária; 6) campanha publicitária voltada ao turismo estadual e; 7) incentivos de crédito e fiscais.

Quadro 2. Resumo de entrevistas: representantes de organizações do mercado turístico e representantes dos órgãos públicos estaduais e municipais de Belém, Salvaterra e Soure. Fonte: entrevistas realizadas entre os meses de novembro e dezembro de 2020.

\begin{tabular}{|c|c|}
\hline \multicolumn{2}{|r|}{ NÍVEL ESTADUAL } \\
\hline AGENTE & AÇÕES \\
\hline SETUR & $\begin{array}{l}\text { Plano de Retomada do Turismo; reuniões com mercado, gestores municipais e academia; trabalho com } \\
\text { o Banpará, Caixa e BASA; atualização de mídias sociais da secretaria; realização de seminários, imersão } \\
\text { digital, formação de condutores de trilhas e caminhadas; conscientização CADASTUR; criação de } \\
\text { newsletters; contato com operadoras norte americanas; ações promocionais no Aeroporto e } \\
\text { Instagram; consultoria online para empresários; colaboração junto a SESMA para a elaboração de } \\
\text { protocolos de vigilância sanitária; lançamento "Redescobrindo o Pará"; Feira Internacional de Turismo } \\
\text { de Gramado. }\end{array}$ \\
\hline ABRASEL & $\begin{array}{l}\text { Pedido de cumprimento de acordos de pagamento entre as concessionárias de energia e água com os } \\
\text { proprietários de bares, restaurantes e similares; conflitos com clientes que recusam seguir as medidas } \\
\text { sanitárias e distanciamento social; nenhuma ação por parte do MTUR; distanciamento da prefeitura } \\
\text { municipal; linhas de crédito não atenderam a maioria dos empresários devido à dificuldade de } \\
\text { pagamento dos débitos da empresa. }\end{array}$ \\
\hline ABRACS & $\begin{array}{l}\text { Articulação para a retomada dos eventos com a prefeitura de Belém, Ananindeua e Castanhal; ausência } \\
\text { de outros municípios; ausência de políticas especificas para o setor. }\end{array}$ \\
\hline ABAV & Busca de recursos junto ao MTUR; desconhecimento de ações SETUR; ausência de auxílios financeiros; \\
\hline $\mathrm{ABIH}$ & $\begin{array}{l}\text { Afastamento de funcionários; concessão de crédito ao cliente; acesso ao crédito bancário para } \\
\text { empresas não-negativadas; empréstimos de valores muito baixos por parte do banco estadual; busca } \\
\text { por incentivos fiscais; redução de pagamento de taxas de energia elétrica, água e afins; pedido de } \\
\text { revisão dos impostos municipais na hotelaria, IPTU e ISS. }\end{array}$ \\
\hline CETUR & $\begin{array}{l}\text { Acordos de suspensão de contrato ou de redução da jornada de trabalho; aumento das linhas de } \\
\text { crédito para as empresas; ações promocionais para o turismo doméstico regional; busca por incentivos } \\
\text { fiscais; inauguração de obras da prefeitura de Belém previstas antes da pandemia; adiamento de } \\
\text { eventos e ações promocionais por parte do Governo estadual. }\end{array}$ \\
\hline SINGTUR & $\begin{array}{l}\text { Comissão para medidas de prevenção e funcionamento dos equipamentos turísticos; zoneamento de } \\
\text { áreas de maior risco; autorizações para realização das excursões; fortalecimento do turismo regional; } \\
\text { auxílio emergencial do governo federal; crédito BANPARÁ; sensação de abandono pelos últimos } \\
\text { Governos; parceria com a SEMOB, SENAC, ABAV e SETUR; fiscalização de empresas e guias irregulares; } \\
\text { participação no Fórum Estadual de Turismo; participação no Plano Municipal de Turismo; parceria }\end{array}$ \\
\hline
\end{tabular}




\begin{tabular}{|c|c|}
\hline & $\begin{array}{l}\text { MTUR na digitalização da carteira de guia de turismo e na qualificação com cursos de idiomas; ações } \\
\text { independentes do FOMENTUR. }\end{array}$ \\
\hline \multicolumn{2}{|r|}{ NÍVEL REGIONAL } \\
\hline ATM & $\begin{array}{l}\text { Liberação de crédito; auxílio emergencial do governo federal; marketing turístico digital; PRONAMPE; } \\
\text { pedido de flexibilização de pagamento do IPTU e demais taxas da prefeitura; pedido de flexibilização } \\
\text { da taxa de recolhimento mensal de pequenos e microempreendedores individuais; parceria Rota do } \\
\text { Queijo do Marajó; Amazônia Marketing; Sinalização turística. }\end{array}$ \\
\hline $\begin{array}{l}\text { SEBRAE } \\
\text { MARAJÓ }\end{array}$ & $\begin{array}{l}\text { Investe Turismo; parceria BANPARÁ para o Fundo Esperança; assessoria marketing digital; assessoria } \\
\text { para financiamentos e empréstimos; capacitação financeira e reservas; articulação com o Governo } \\
\text { estadual para o cumprimento das medidas sanitárias estaduais; dificuldades de acesso à internet } \\
\text { para participar das reuniões e tratativas de modo virtual; parceria com instituições do Sistema S. }\end{array}$ \\
\hline \multicolumn{2}{|r|}{ NÍVEL MUNICIPAL } \\
\hline \multicolumn{2}{|r|}{ BELÉM } \\
\hline SEBRAE BELÉM & $\begin{array}{l}\text { Capacitações; suporte em medidas sanitárias, com entrega de material de higiene em } \\
\text { estabelecimentos de turismo; ações promocionais junto aos empreendedores; implementação da } \\
\text { plataforma "Amazônia Marketing"; parceria SEDEME e BANPARÁ; Investe Turismo. }\end{array}$ \\
\hline BELEMTUR & $\begin{array}{l}\text { Proposta de implementação e apoio do Fundo Ver-o-Sol para o turismo; inauguração de obras e } \\
\text { reformas previstas antes da pandemia; ausência de autonomia financeira. }\end{array}$ \\
\hline \multicolumn{2}{|r|}{ SOURE } \\
\hline SECTUR SOURE & $\begin{array}{l}\text { Implementação de protocolos e medidas sanitárias; controle de acesso aos pontos turísticos, em } \\
\text { especial, praias; atuação das comunidades locais no enfrentamento da covid. }\end{array}$ \\
\hline
\end{tabular}

Dentre os questionamentos e pedidos de acordos negociados com a gestão pública estadual, relatados no quadro 2, chama atenção as medidas de mitigação aos impactos econômicos, como o realizado em abril de 2020, que junto às companhias responsáveis pelo fornecimento de água e energia elétrica estabeleceu a suspensão de cortes dos serviços por falta de pagamento pelo período de 90 dias. Os informantes solicitam a prorrogação desse acordo, principalmente, pela instabilidade financeira estendida ao segundo semestre de 2020 e ano de 2021. Os representantes das entidades ligadas ao mercado também requerem o abono ou redução das taxas na arrecadação de impostos da base estadual e municipal como ISS e ICMS.

Conforme estabelecido pelo Programa Emergencial de Manutenção do Emprego e da Renda (BEm) do Ministério da Economia, por meio da MP no 936, de 01 de abril de 2020, houve ainda a suspensão de contratos trabalhistas e redução da jornada de trabalho e salários dos trabalhadores. Prorrogado por duas vezes durante o último ano, o programa foi suspenso em 31 de dezembro de 2020 com a instituição do fim do estado de calamidade pública por parte do Governo federal, o que difere da realidade visto que o quadro pandêmico permanece sem previsão de encerramento.

No que diz respeito às ações da prefeitura, destaca-se a BELEMTUR, no município de Belém, que se concentrou em realizar a entrega de planos, obras e reformas previstos anteriormente à pandemia, antes que ocorra a mudança de gestão, como a entrega do aplicativo "Explore Belém", uma parceria com a Faculdade 
Pan-Amazônica (FAPAN-Estácio), voltado para a consulta aos atrativos e equipamentos turísticos da capital, a inauguração do Terminal Turístico da Praça Princesa Isabel e do Solar da Beira, no Complexo do Ver-o-Peso, como também o lançamento do Plano Municipal de Turismo, em dezembro de 2020. Não apresentando nenhuma ação específica em alinhamento com as medidas sanitárias ou decretos em combate à pandemia da covid-19.

Preocupa o desinteresse e falta de articulação de algumas das entidades da sociedade civil organizada com os órgãos governamentais quanto à participação nos Fóruns de discussão do turismo em nível municipal e estadual e, principalmente, a falta de continuidade de projetos e ações em andamento por parte das antigas gestões, como evidenciado pelo representante da BELEMTUR, que reclama a baixa autonomia política e financeira da Coordenadoria.

Durante a pandemia da covid-19, a atuação governamental em prol das empresas turísticas organizou projetos e ações que prestam assistência técnica e informacional específica. Quanto a isso, Rodrigues (2018) tem como referência o planejamento de Rotas Turísticas, em que são fornecidos apoio promocional, inventários de oferta turística, equipamentos e capacitações às prefeituras e aos estabelecimentos comerciais inseridos nos roteiros. Parcerias com consultorias, como as oferecidas pelo SEBRAE e demais instituições do Sistema $S^{6}$, criam mercadorias informacionais, pela gama larga que abrangem e pelo apoio técnico que disponibilizam para cursos e treinamentos.

A publicidade e o apoio governamental são fundamentais para a existência dos circuitos econômicos do turismo, o primeiro, por ser uma das armas utilizadas para modificar os gostos e deformar o perfil da demanda; e o segundo, por sua capacidade de viabilizar capital social (overhead) fixo e infraestrutura (SANTOS, 2008). Assim, as agências de receptivo turístico podem contar também com recursos e acesso à informação por meio de revistas especializadas e, mais recentemente, pelo marketing digital em plataformas virtuais de comercialização de produtos e serviços turísticos, como a plataforma Amazônia Marketing e Visit Pará, citadas no quadro 2, e nas mídias sociais (Facebook, Instagram e Whatsapp, principalmente). Contudo, em municípios do arquipélago do Marajó e mesmo em Belém, como no caso de algumas das ilhas, as dificuldades de acesso à internet tornam as articulações ainda incipientes, ocorrendo uma adaptação parcial dos moradores e comerciantes às novas tecnologias.

Programas de incentivo ao turismo são criados a cada mudança de gestão, como é o caso do "Investe Turismo", planejado pelo Governo federal por meio da EMBRATUR e MTUR em parceria com o SEBRAE, que

\footnotetext{
${ }^{6}$ Fazem parte do sistema S: Serviço Nacional de Aprendizagem Industrial (SENAI); Serviço Social do Comércio (SESC); Serviço Social da Indústria (SESI); e Serviço Nacional de Aprendizagem do Comércio (SENAC). Existem ainda os seguintes: Serviço Nacional de Aprendizagem Rural (SENAR); Serviço Nacional de Aprendizagem do Cooperativismo (SESCOOP); e Serviço Social de Transporte (SEST).
} 
previa capacitações, ações de marketing e apoio à comercialização de produtos, que segundo informações dos representantes do SEBRAE, teve as mobilizações interrompidas por mudanças na remodelagem na pasta da EMBRATUR, bem como no redirecionamento dos recursos financeiros por parte do referido Governo.

A gente tem um convênio com o Ministério do Turismo que é o "Investe Turismo" (...) Ações voltadas para a estratégia de fortalecimento do turismo no Brasil. Então, tinha inclusive ações de promoção, realmente, fora do Brasil e tudo mais. Aí, houve o impasse entre instituições, que foi, na verdade, uma medida Provisória para transferência do investimento para a criação da EMBRATUR (...) que foi a última remodelagem brasileira que houve agora no governo Bolsonaro. Baseado nisso, houve uma série de reuniões a respeito da perspectiva de 200 milhões de cortes orçamentários. O SEBRAE se manifestou porque ele já usava (Representante SEBRAE Belém, dezembro de 2020).

(...) Eu vou começar pelo Ministério do Turismo que antes da pandemia criou um projeto chamado Investe Turismo, em parceria com o SEBRAE e com a EMBRATUR. Esse projeto consistia em organizar, vamos dizer assim, criar e organizar roteiros turísticos, para que esse roteiro pudesse fazer parte de um roteiro nacional e internacional. (...) Ele não chegou a sua conclusão (...) por conta dessa mexida e logo em seguida veio a pandemia, onde nós ainda permanecemos com parceria com o Ministério do Turismo. Nesse momento, o SEBRAE conseguiu mais recursos para que a gente pudesse trabalhar com turismo, na verdade, foi um saldo do investimento, porque era muito maior, mas acabou ficando o valor muito menor (Representante SEBRAE MARAJó, dezembro de 2020).

De modo geral, observou-se com as entrevistas realizadas com as diferentes instituições e organizações civis ligadas ao turismo, que as organizações sociais e empresariais tiveram grande importância no momento de crise endêmica. Associações empresariais de diferentes setores da cadeia de turismo mobilizaram-se, antes mesmo das primeiras medidas anunciadas pelo governo federal. A rede estabelecida no interior dessas instituições subsidiou o compartilhamento de informações para que as empresas e representações sociais pudessem ter conhecimento da magnitude dos impactos.

No entanto, observou-se que as relações estabelecidas entre as diferentes esferas do poder público e pelos representantes do mercado rivalizam entre si, gerando relações permeadas por contradições, conflitos de naturezas e escalas diversas, não ocorrendo de modo tranquilo. Esse processo nebuloso e lento dificulta o planejamento satisfatório do turismo local para um período pós-pandêmico, pois os agentes têm interesses, por vezes, particulares e divergentes, tal desentendimento privilegia pequenos grupos em detrimento de outros, o que torna ainda mais complexa a análise.

O quadro $3^{7}$ trata sobre as principais estratégias pensadas para um período de transição pós-pandêmico, nele, observou-se que os entrevistados ligados ao poder público e organizações civis inerentes à iniciativa privada, enfatizaram a importância do fomento ao turismo doméstico e regional, bem como a necessidade de investimento em qualificação, aumento dos limites de crédito, financiamento para as empresas e marketing digital voltado para ampliação das atividades de comercialização de produtos e serviços turísticos.

\footnotetext{
${ }^{7}$ Nas entrevistas, realizadas no período entre novembro e dezembro de 2020, houveram dificuldades de contato com representantes de entidades de classe que atuam exclusivamente no município de Salvaterra, o principal motivo alegado se deve ao período eleitoral e às dificuldades de acesso à internet para realização da entrevista.
} 
Quadro 3. Regiões Turísticas de Belém e Campos do Marajó: resumo das principais estratégias pensadas para o período póspandemia da covid-19. Fonte: entrevistas realizadas entre os meses de novembro e dezembro de 2020.

\begin{tabular}{|c|c|}
\hline \multicolumn{2}{|r|}{ NÍVEL ESTADUAL } \\
\hline AGENTE & ESTRATÉGIAS \\
\hline SETUR & $\begin{array}{l}\text { Incentivo à realização de viagens de acordo com as normas de segurança; realização de Famtour } \\
\text { e Press trip; investimento de } 500 \text { mil reais em compra de mídia aeroportuária e mobiliária urbana; } \\
\text { reabertura do edital de fomento a eventos turísticos, no pós-pandemia. }\end{array}$ \\
\hline ABRASEL & Treinamentos e capacitações. \\
\hline ABRACS & $\begin{array}{l}\text { Estabelecimento de parcerias para linhas de crédito específicas para os empresários do setor de } \\
\text { eventos; incentivo à formalização e ao associativismo no setor de eventos. }\end{array}$ \\
\hline ABAV & Fomento ao turismo receptivo e interno a partir de 2022. \\
\hline $\mathrm{ABIH}$ & Nenhuma estratégica específica, somente quando houver a vacinação da população. \\
\hline $\begin{array}{l}\text { CETUR } \\
\text { FECOMERCIO }\end{array}$ & $\begin{array}{l}\text { Plano Municipal de Turismo; fundo de arrecadação municipal para taxas de serviços hotéis e } \\
\text { restaurantes; Programa "Passaporte Pará" de descontos e promoções para o turismo regional; } \\
\text { presença digital das empresas. }\end{array}$ \\
\hline SINGTUR & $\begin{array}{l}\text { Ordenamento do turismo por parte da prefeitura; melhores condições de comunicação e estrutura } \\
\text { entre as entidades civis e governamentais sobre os roteiros e pacotes; regularização e guias; } \\
\text { fiscalização sobre empresas e guias ilegais; roteiros regionais com número reduzido de pessoas; } \\
\text { mudança no perfil e tamanho dos grupos de turistas; capacitações junto às comunidades receptoras; } \\
\text { maior presença digital; formação em modelo híbrido. }\end{array}$ \\
\hline \multicolumn{2}{|r|}{ NIVEL REGIONAL } \\
\hline ATM & Nenhuma medida prevista. \\
\hline SEBRAE MARAJÓ & Assessoria em marketing digital; capacitação; assessoria para serviços delivery. \\
\hline \multicolumn{2}{|r|}{ NÍVEL MUNICIPAL } \\
\hline \multicolumn{2}{|r|}{ BELÉM } \\
\hline SEBRAE BELÉM & $\begin{array}{l}\text { Assessoria digital ao empreendedor nas redes sociais; Capacitação; plataforma Amazônia Marketing; } \\
\text { apoio a estruturação do turismo nas ilhas; regularização; Apoio à legislação: lei do empreendedor } \\
\text { (Sala do empreendedor em parceria com as prefeituras); apoio ao crédito do empreendedor via } \\
\text { BANPARÁ; consultoria empresas parcerias do estado; Em nível federal, paralisação das atividades do } \\
\text { Programa "Investe Turismo"; atuação nos conselhos ambientais e turísticos municipais. }\end{array}$ \\
\hline BELEMTUR & $\begin{array}{l}\text { Incentivo financeiro aos micros e pequenos empreendedores; qualificação; implementação de } \\
\text { centros de turismo comunitário nas ilhas; Plano Municipal de turismo; parceria com a academia na } \\
\text { implementação do aplicativo "Explore Belém"; }\end{array}$ \\
\hline \multicolumn{2}{|r|}{ SOURE } \\
\hline SECTUR SOURE & Previsão de criação de um Sistema Municipal de Turismo; capacitações junto ao SEBRAE. \\
\hline
\end{tabular}

Mesmo a pandemia da covid-19 sendo uma ameaça de repercussão global, pode assumir diferentes feições regionais, onde as desigualdades tendem a se aprofundar. Portanto, no planejamento e gestão desse novo momento do turismo regional paraense destacam-se para além das propostas do Projeto "Abre Caminho", a sugestão de retorno de projetos como o "Passaporte Pará" (PARÁ, 2015) que, conforme relato 
do informante do CENTUR/FECOMÉRCIO, ex-secretário adjunto de Estado de Turismo da antiga gestão estadual, é voltado para criação de pacotes e roteiros regionais diferenciados, inicialmente, para os servidores públicos e, posteriormente, para a população.

Nós não temos uma estratégia montada. (...) tive a oportunidade de conversar com o atual secretário, de estabelecer um negócio chamado "Passaporte Pará" para que os milhares de empregados do governo do Pará pudessem financiar suas viagens de férias, desde que elas fossem feitas dentro do Estado do Pará. Por uma questão de tecnologia no Banco do Estado, por uma questão técnica no Banpará, isso não foi para frente (Representante CETUR/FECOMERCIO, dezembro de 2020).

Dentre os reforços para as ações de marketing, tem-se o marketing digital, atualmente, um dos meios mais poderosos de controle da demanda turística e da população em geral, cujo uso de plataformas virtuais de comercialização dos produtos turísticos prevê o aumento das receitas nas visitações pelo Estado. Para Rodrigues (2018), esse processo é legitimado pela escolha de atores carismáticos (membros do poder público, blogueiros ou lideranças locais), que por meio da atuação nas mídias sociais, podem contribuir com o consenso da importância das políticas espaciais. Preocupa-se, assim, com o risco de minimização e obscurecimento dos reais problemas encarados pelas comunidades.

Ademais, em um cenário pós-pandemia da covid-19, as entidades governamentais e representantes do trade turístico assumem a qualificação e a capacitação como fundamentais aos comerciantes e trabalhadores envolvidos na atividade turística. O projeto "Abre Caminho" e a maioria dos relatos dos entrevistados corroboram com essa afirmação, pois ao disponibilizar cursos, eventos, viagens e treinamentos aos empreendedores, procura-se manter o ambiente de competição interurbana dentro das regiões. Assume-se que a partir da realização dos cursos e capacitações promovidos pelos órgãos públicos e entidades de classe municipais e estaduais de turismo, vê-se também uma oportunidade de ampliação da empregabilidade dos trabalhadores e da renda familiar.

Esses agentes vão em busca de maior apoio de instituições financeiras que disponibilizam fundos, linhas de crédito e financiamentos, como o Fundo Esperança do BANPARÁ ${ }^{8}$, intensificados no período de pandemia, capazes de proporcionar, por exemplo, a compra de equipamentos, mobiliário, regularização da folha de pagamento, etc. Contudo, pressupõe-se o aumento do endividamento entre os comerciantes que sobreviverem ao período de crise da covid-19.

As entidades pertencentes ao trade turístico devem ter a premissa de representar, além das inclinações particulares, os interesses dos estabelecimentos que não possuem condições de contratar empresas de

8 O Fundo Esperança alocou $\mathrm{R} \$ 200.000 .000,00$ para a realização de operações, limitadas a $\mathrm{R} \$ 5.000,00$ (cinco mil reais) para Microempreendedores Individuais; $R \$ 10.000,00$ (dez mil reais) para Microempresas; e $R \$ 15.000,00$ (quinze mil reais) para Empresas de Pequeno Porte e Cooperativas. As operações subsidiadas têm prazo uniforme de até 36 (trinta e seis) meses, com carência de 90 (noventa) dias para o pagamento da primeira parcela, e taxa de juros uniforme de $0,2 \%$ (dois décimos por cento) ao mês (PARÁ, 2020). 
consultoria e de marketing. A rapidez na difusão propiciada pelo uso de tecnologias é relevante, até mesmo para garantir a segurança dos comerciantes que, da mesma maneira que a maioria dos moradores, não possuem capacidade de estender as pequenas atividades e comércios para além de suas localidades.

Nesse processo de (re)organização estratégica do espaço pós-pandemia, vale destacar que, em 2021, deu-se início à nova gestão municipal, cujos interesses múltiplos, muitas vezes conflituosos, por vezes, não priorizam ações que visem o desenvolvimento em nível local do turismo.

\section{CONSIDERAÇÕES FINAIS}

Esse artigo foi focado em duas regiões turísticas do Estado do Pará: a Região Turística de Belém e a Região Turística dos Campos do Marajó, com o objetivo de analisar como vem sendo pensado o planejamento e a gestão do turismo mediante a implementação de medidas sanitárias, de distanciamento social e demais políticas mitigadoras dos impactos da pandemia da covid-19, e sua aplicabilidade nas realidades dos municípios Belém, Soure e Salvaterra.

A análise das Políticas e medidas de enfrentamento dos impactos da covid-19 pela gestão pública e representantes do mercado turístico dessas regiões apontam vários decretos estabelecidos durante o ano de 2020, para o Estado do Pará e para os 03 municípios selecionados. Assim como ações, como o Projeto "Abre Caminho", elaborado pela SETUR, que reforça as ações instituídas pelo Programa RETOMAPARÁ, que tratou da retomada do setor por meio da aplicação de medidas de distanciamento controlado e protocolos específicos para reabertura gradual e funcionamento de segmentos de atividades econômicas e sociais.

O projeto "Abre Caminho", cujas as estratégias e ações mais discutidas entre os representantes do poder público e da iniciativa privada foram as relacionadas à obtenção de créditos e auxílios financeiros, incentivos fiscais, estratégias de marketing e qualificação e implementação de protocolos de segurança sanitária, ainda está em fase de implementação e sem dados disponíveis nos órgãos oficiais, portanto, os resultados serão levantados em um próximo momento desta pesquisa. Posto isto, em julho de 2020, foi lançada uma cartilha de orientações sobre parcerias com entidades bancárias e financeiras como o BANPARÁ, Banco da Amazônia, BNDES, Caixa Econômica e Banco do Brasil, além de bancos privados e FUNGETUR.

De acordo com os entrevistados do SEBRAE, alguns dos recursos advindos de programas de incentivo ao turismo, anteriores ao quadro pandêmico, como é o caso do "Investe Turismo", planejado pelo Governo federal por meio da EMBRATUR e MTUR em parceria com o SEBRAE, ainda estão sendo utilizados. A partir dele, algumas das capacitações, fornecimentos de equipamentos de proteção e higiene, ações de marketing e apoio à comercialização de produtos ainda estão sendo disponibilizadas aos comerciantes parceiros desta entidade. 
Nas entrevistas realizadas com as diferentes instituições e organizações civis ligadas ao turismo, observou-se que as organizações sociais e empresariais tiveram grande importância no momento de crise endêmica. Por outro lado, percebe-se que as relações estabelecidas entre as diferentes esferas do poder público e pelos representantes do mercado rivalizam entre si, gerando relações permeadas por contradições, conflitos de naturezas e escalas diversas.

Nesse âmbito, no que refere às principais estratégias pensadas para um período de transição póspandêmico, observou-se que os entrevistados ligados ao poder público e organizações civis inerentes à iniciativa privada, enfatizaram a importância do fomento ao turismo doméstico e regional, bem como a necessidade de investimento em qualificação, aumento dos limites de crédito, financiamento para as empresas e marketing digital voltado para ampliação das atividades de comercialização de produtos e serviços turísticos.

Por fim, a partir da análise das medidas sanitárias de restrição a circulação de pessoas e ao transporte; das entrevistas realizadas com representantes de organizações do trade turístico e representantes dos órgãos públicos estaduais e municipais e; da análise das principais estratégias pensadas para o período pós-pandemia da covid-19, aponta-se que a Pandemia impactou de forma significativa o setor do turismo durante o ano de 2020. Com a mudança na gestão municipal a partir do ano de 2021 , espera-se que as ações visem perspectivas que garantam os interesses coletivos locais.

\section{REFERÊNCIAS}

BECKER, B. Amazônia. 5. ed. São Paulo: Ática, 1997.

BELÉM. Decreto no 95955, de 18 de março de 2020. Legisweb. Disponível em: https://www.legisweb.com.br/legislacao/?id=390865. Acesso em: 10 nov. 2020.

BELÉM. Decreto no 96340, de 25 de maio de 2020. Legisweb. Disponível em: https://www.legisweb.com.br/legislacao/?id=395986. Acesso em: 10 nov. 2020.

BELÉM. Decreto no 96378, de 01 de junho de 2020. Legisweb. Disponível em: https://www.legisweb.com.br/legislacao/?id=396337. Acesso em: 10 nov. 2020.

BRASIL. Ministério do Turismo. Relatório estatístico do Fungetur: dezembro de 2020. Brasília, 2020a. Disponível em: https://www.gov.br/turismo/pt-br/acesso-a-informacao/acoes-eprogramas/fungetur/transparencia/relatorio-estatistico-do-fungetur-marco_2021.pdf. Acesso em: 09 fev. 2021.

BRASIL. Ministério do Turismo. Recursos do Fungetur contratados desde 2018, por instituição. Brasília, 2020b Disponível em: hhttps://www.gov.br/turismo/pt-br/acesso-a-informacao/acoes-eprogramas/fungetur/transparencia/ranking-marco-2021.pdf. Acesso em: 09 fev. 2021.

BRASIL. Ministério do Turismo. Plano de retomada do turismo. Brasília, 2020c. Disponível em: https://retomada.turismo.gov.br/wpcontent/uploads/2020/11/Cartilha-Retorno-pelo-Turismo-On-line-min.pdf. Acesso em: 09 fev. 2021. 
BRASIL. Decreto-lei no 1.439, de 30 de dezembro de 1975. Brasília, 1975. Disponível em:

http://www.planalto.gov.br/ccivil 03/Decreto-Lei/1965-1988/Del1439.htm\#art13. Acesso em: 09 fev. 2020.

CRUZ, R. O evento da covid-19 e seus impactos sobre o setor turismo: em busca de uma análise multi e trans-escalar. Observatório de inovação do turismo - Revista Acadêmica, v. XIV, n. esp., dez. 2020.

EMPRESA BRASILEIRA DE INFRAESTRUTURA AEROPORTUÁRIA

(INFRAERO). Dados operacionais - estatísticas (2019 e 2020). Disponível em: https://transparencia.infraero.gov.br/estatisticas/ . Acesso em: 03 set. 2020.

FGV - Fundação Getúlio Vargas. Impacto econômico do Covid 19 - Propostas para o turismo brasileiro. Rio de Janeiro: FGV, abr. 2020. Disponível em:

https://fgvprojetos.fgv.br/sites/fgvprojetos.fgv.br/files/01.covid19 impactoeconomico v09 compressed 1.pdf. Acesso em: 08 fev. 2021.

FUNDAÇÃO OSWALDO CRUZ. Centro de Estudos e Pesquisas em Emergências e Desastres em Saúde (Cepedes). A gestão de riscos e governança na pandemia por Covid-19 no Brasil: análise dos decretos estaduais no primeiro mês, relatório técnico e sumário executivo. Rio de Janeiro: Cepedes/ENSP/Fiocruz, 2020.

GONZÁLEZ, M. V. La pandemia como problema de política pública. In: Cruz, M. S.;

MARTíN, R. H.; FUMERO, N. P. (Org) Turismo pos-COVID-19 Reflexiones, retos y oportunidades. Laguna, España: Cátedra de Turismo CajaCanarias-Ashotel de la Universidad, 2020.

HALL, C. M.; SCOTT, D.; GOSSLING S. Pandemics, transformations and tourism: be careful what you wish for, Tourism Geographies, 22:3, 577-598, 2020.

LEFEBVRE, H. O direito à cidade. 5. ed. São Paulo: Centauro, 2001.

MEGUIS, T. R. B. Transporte fluviomarítimo e turismo: a viagem à Soure e as perspectivas de desenvolvimento local. $2018.223 \mathrm{f}$. Dissertação (Mestrado) - Universidade Federal do Pará, Núcleo de Altos Estudos Amazônicos, Pós-Graduação em Desenvolvimento Sustentável do Trópico Úmido, Belém, 2018.

MOLINA, F. Turismo e produção do espaço: o caso de Jericoacoara. 2007. 150 f. Dissertação (Mestrado em Geografia Humana) Programa de Pós-Graduação em Geografia Humana, Faculdade de Filosofia, Letras e Ciências Humanas, Universidade de São Paulo, 2007.

ORGANIZAÇÃO MUNDIAL DO TURISMO (OMT). Apoyo al empleo y a la economía a través de los viajes y el turismo. Llamamiento a la acción para mitigar el impacto socioeconómico de la Covid-19 y acelerar la recuperación. 1 de abril de 2020. Disponível em: https:// webunwto.s3.eu-west-1.amazonaws.com/s3fs-public/2020-04/COVID19_Recommendations_ES.pdf. Acesso em: 08 de fev. 2021.

PARÁ. Lei no. 9.051, de 14 de maio de 2020. Agência Pará. Disponível em: https://agenciapara.com.br/noticia/19537/. Acesso em: 28 fev. 2021.

PARÁ. Companhia Paraense de Turismo. Diagnóstico da área e das atividades turísticas do Pólo Belém - PA. Belém: Paratur; CHIAS Marketing, 2009.

PARÁ. Governo do Estado. Plano de desenvolvimento do turismo do estado do Pará (PDTPA). Belém: Companhia Paraense de Turismo - PARATUR/ THR - Assessoria em Turismo Hotelaria e Recreação, 2001.

PARÁ. Governo do Estado. Plano Ver-o-Pará - plano estratégico de turismo do estado do Pará. Belém: Paratur; CHIAS Marketing, 2011 (Fase II: o planejamento estratégico).

PARÁ. Governo do Estado. Plano Ver-o-Pará: relatório de implantação 2012-2014. Belém: SETUR, 2015.

PARÁ. Secretaria de Estado de Turismo. Polo Belém. Disponível em: http://www.setur.pa.gov.br/polo-bel\%C3\%A9m. Acesso em: 12 nov. 2020.

PARÁ. Secretaria de Estado de Turismo. Portaria no 164/2019/Geps/Setur. Dispõe sobre a regionalização do turismo no Estado do Pará e dá outras providências. Belém: Setur, 2019.

PARÁ. Secretaria de Estado de Turismo. Projeto Abre Caminho. Belém: Setur, 2020. 
RODRIGUES, A. A produção do espaço pelo e para o turismo na Área de Proteção Ambiental da llha do Combu (Belém-Pará). 2018. 331 f. Dissertação (Mestrado em Planejamento do Desenvolvimento) - Programa de Pós-Graduação em Desenvolvimento Sustentável do Trópico Úmido, Núcleo de Altos Estudos Amazônicos, Universidade Federal do Pará, Belém, 2018.

SANTOS, M. A natureza do espaço. 8. ed. São Paulo: Edusp, 2014.

SEDEME. Secretaria de Estado de Desenvolvimento Econômico, Mineração e Energia. Balanço do primeiro ano do programa Pará 2030. Belém: Sedeme, 2017.

SILVA, C.; SOARES, R.; MACHADO, W.; ARBILLA, G. A Pandemia de Covid-19: Vivendo no Antropoceno. Revista Virtual Química. v. 12, n. 4, p. 1001-1016, 2020.

SALVATERRA. Decreto no. 07/2020 de 25 de março de 2020. Extra do Pará. Disponível em:

https://extradopara.com/2020/03/25/exclusivo-prefeito-de-salvaterra-decreta-barreira-sanitaria-no-municipio-confira-o-decreto/. Acesso em: 10 nov. 2020.

SALVATERRA. Procedimento Administrativo no. 000194-343, de 4 de junho de 2020. Ministério Público do Estado do Pará. Disponível em: http://www.mppa.mp.br/data/files/D8/56/19/6F/A2682710BBF8A527180808FF/ACP-\%20Decreto\%20Salvaterra\%20\%20Revogacao.pdf. Acesso em: 30 out. 2020.

SOURE. Decreto no. 007/2020 de 19 de março de 2020. Decreto no. 009/2020 de 21 de março de 2020. Prefeitura Municipal de Soure. Disponível em: https://www.soure.pa.gov.br/covid-19/atos-normativos-covid-19/. Acesso em: 23 mar. 2021.

TEBERGA, A. Turismo perde mais de 300 mil empregos em 2020. Labor movens. Disponível em: https://www.labormovens.com/post/turismo-foi-respons\%C3\%A1vel-por-45-dos-empregos-perdidos-em-2020-no-brasil\&gt;. Acesso em: 10 fev. 2020. 